\title{
Das maneiras de se escrever uma pesquisa
}

\section{Resumo}

Como criar textos advindos de pesquisas entre a Arte e a Educação? Desesperos aparecem quando precisamos expressar os movimentos de uma pesquisa na escrita. Para tanto, o maneirismo, estilo descrito na historiografia da arte mostrando tendências não ortodoxas de criação, inspira um percurso de aprendizagens distinto do estabelecimento de passos metodológicos. Métodos e maneiras aqui são diferenciados a fim de que possamos pensar a textualização de uma pesquisa por outra via que não as dos textos científicos e técnicos. Com o legado de Nietzsche, referenda-se o pensamento de Deleuze e a esquizoanálise que esse desenvolveu com Guattari. Os conceitos de rizoma, linha de fuga e máquina de guerra são apresentados para tratarmos o problema de "como" fazer um trabalho acadêmico que não seja mera reprodução do que já foi escrito.

Palavras-chave: maneirismo, rizoma, esquizoanálise, desespero

\section{Of manners to write a research}

\begin{abstract}
How to create a text from research between Art and Education? Much despairs come when we need to express moviments of search in writing. Here, the mannerism, style described in art's historiography, inspire a course of learning distinct from established methodological steps. Methods are distinguished of ways, mores and manners for to think about research's textualisation by another route than the scientific and technical texts. With Nietzsche's legacy, concerns Deleuze's thought and schizoanalyses that him developed with Guattari. Concepts of rizhome, line of fugue and war machine are presentes for treat the problem of "how" to make an academical work that no is a reproduction what has been written.
\end{abstract}

Keywords: mannerism, rizhome, squizoanalyses, despair

"Só era puro quem fosse desesperado" ${ }^{1}$

Antonin Artaud

Não é sem desespero que nos embrenhamos na louca tessitura de um texto. A agonia talvez seja maior quando esse texto vem da exigência de se colocar em palavras o

\footnotetext{
${ }^{1}$ In: Escritos de Antonin Artaud. Porto Alegre: LP\&M, 1986, p.90. 
processo de uma pesquisa. E escrever se torna ainda mais desesperador quando os modos conhecidos do que seja pesquisar começam a se tornar enfadonhos ou simplesmente se esfacelam diante do que estamos estudando: estudo que se pressupunha "fundamentar" as investigações, as análises e as críticas que propúnhamos fazer. Mas o que fazer quando os autores estudados, ao invés de fornecerem um solo seguro para erigirmos o trabalho em forma de texto, simplesmente nos tiram o chão? Sem nenhuma esperança de que surjam asas para nos salvar da queda somos levados a voar com as palavras. No espaço liso do voo somos obrigados a pensar. Não sabemos mais o que fazer, mas temos que fazer. Então, assombrados e maravilhados, a única coisa que sabemos é que, agora, vamos ter que inventar.

Desesperos assim acontecem quando encontramos a monstruosa obra de Gilles Deleuze. Obra monstruosa, não apenas pela quantidade do que foi escrito ou por seu caráter heteróclito, cuja promiscuidade de autores e referências desconcerta os mais variados campos do saber. É certo que nos assustamos com as velocidades infinitas e as multiplicidades junto às quais somos arrastados quando tocamos o imensurável corpo do pensamento deleuziano, mas o que efetivamente nos desespera é sua proximidade com o impensado. Como não podemos pensá-lo apenas podemos vislumbrar a "linha feiticeira" que demarca sua proximidade. Chegar perto dessa linha é penetrar na zona limítrofe, alheia a tudo o que já se conhece, para sorver imperceptíveis partículas do que ainda não está criado. Aprendemos, com Nietzsche, Artaud e outros criadores, que tal sorvo enlouquece. A esquizoanálise, criada por Deleuze junto com Félix Guattari, faz a cartografia desse território selvagem, perigoso e potencialmente fatal, onde as linhas de fuga desembocam. Zona micropolítica estratégica, constitui territórios moleculares compostos por multiplicidades caóticas que fomentam as criações. É nessa zona fronteiriça, desterritorializadora, onde se experimenta a lisura aterradora em face ao spatium nunca antes pensado, que se vive o devir inumano da filosofia de Deleuze. Ali, se encontra a monstruosidade do que se cria, imiscuída com o impensável incriado, do qual nada se pode esperar. É isto que apavora e pode enlouquecer.

Nesse encontro, a diferença, imprescindível para a criação, se faz. A estranheza sentida frente ao novo é um acontecimento que força ao pensamento e à criação. O medo de não saber como fazer é paralisante, é preciso um terrível embate contra os pavores de "fazer certo" para se conseguir inventar. Por outro lado, podemos nos manter nos segmentos molares, no espaço estriado da pesquisa dominante e seguir os métodos que "ensinam" um modo de se fazer. Um método é um tipo de programação que implica sempre um 
processo lógico, ordenador, que define um meio para execução de um projeto ou de uma pesquisa e que serve para designar sistemas de classificação ou conjuntos de prescrições. Por método, se supõe certos procedimentos técnicos e científicos que, muitas vezes, envolvem cálculo e experimentação, atrelados aos passos de Descartes, cujo método confunde-se com sua própria doutrina: organização, repetição e correção (PASCAL, 1990).

Para Deleuze, isso é um tipo de adestramento, pois o método é meio de regulagem, um modus operandis cujas premeditações manifestam o senso comum (1988, p.270). A serviço das aparelhagens estatais "um método é o espaço estriado da cogitatio universalis, e traça um caminho que deve ser seguido de um ponto ao outro" (DELEUZE;GUATTARI, 1997, p. 47). Buscar um método previamente determinado é ir atrás do conhecido, seguir um caminho já traçado, trilhado por muitos ou, ao menos, por alguns. Seguir metodologias, embora seja rota segura e garantida, desobriga a pensar. “O método em geral é um meio para nos impedir de ir a tal lugar ou para garantir a possibilidade de sairmos dele" (DELEUZE, 1976, p.90), o fio do labirinto com o qual acabamos enforcados. Embora o pensamento precise de coordenadas, Deleuze não cansa de dizer: só pensamos onde atuam certas forças, lugares extremos, tropicais, frequentados por antropófagos. Para Deleuze, o que força a pensar está longe das "zonas temperadas" e do "homem moral, metódico ou moderado" (idem,p.91). Ao invés de um método sugere, junto com Nietzsche, "uma paidéia, uma formação, uma cultura" (idem, p.90), pois, dificilmente descolado do modelo cartesiano, o método procura sempre descobrir a verdade; criado com a esperança de se alcançar resultados e conclusões, sua meta é o "verdadeiro conhecimento"2.

Ideia transcendente, o saber absoluto sobre o Universo só pode ser pensado por Deus, outro signo da transcendência. Muito "acima" da consciência dos mortais que vivem na carne, o saber absoluto pode ser vislumbrado por meio de dogmas ou mistérios. 0 imaculado conhecimento é como a tênue luz da lua, somente reflete. Sua ordem é arborescente, expressa na árvore do Bem e do Mal, Árvore do Conhecimento, cuja ramagem cresce para alcançar o céu. O conhecimento divino, edênico, que o cristianismo não descola do amor incorporal, ensina a alcançar uma suposta verdade, cujo saber reconquista o paraíso. No início de Mil platôs, Deleuze e Guattari comentam o quanto é

\footnotetext{
${ }^{2}$ Descartes elegeu a matemática como a ciência mais confiável para a obtenção da verdade. A crença de que o conhecimento do universo se expressa prioritariamente em termos numéricos marca todas as concepções racionalistas do saber, sendo fundamental no iluminismo e, posteriormente, para o positivismo. Até os dias de hoje, é comum os cientistas defenderem a ideia de que a linguagem cósmica é matemática.
} 
não descola do amor incorporal, ensina a alcançar uma suposta verdade, cujo saber reconquista o paraíso. No início de Mil platôs, Deleuze e Guattari comentam o quanto é curiosa a predominância da árvore no pensamento ocidental: "da botânica à biologia, a anatomia, mas também a gnoseologia, a teologia, a ontologia, toda filosofia". A metodologia, ao adotar o modelo arborescente, pressupõe finalidades e trata de um modo para ensinar "como fazer", para chegar "lá". Contrapondo-se à ordem transcendente, Deleuze e Guattari, criam o conceito de rizoma como figura do pensamento da imanência, cujo plano não compreende nenhuma instância superior, absolutismos conceituais ou imagens dogmáticas.

Errante, nômade, esse pensamento não pretende chegar a nenhum lugar, apenas saber orientar-se no spatium que constitui o plano. Não há transcendência, o céu não é sua meta, não há mais acima ou abaixo, mas um fundo infinito, horizontalidade plena, superfície, derme sensível onde passam todas as intensidades caóticas em vias de se atualizar. Muito mais do que atingir uma porção do conhecimento do Absoluto ou alcançar a verdade, aprende-se para poder habitar terras estranhas. Aprender é um problema político, pragmático, um modo de conduzir-se em territórios existenciais, a criação de um ethos de encontros. Pois são nos encontros que acontecem nessa errante movimentação, inerente a todo processo de aprendizagem, que nos obrigamos a decifrar os signos. Ninguém aprende com os métodos porque aprendemos "com" o professor, nunca "como" o professor. Não se trata de seguir um método, mas de aprender maneiras de decifração de signos e criação de problemas. Junto ao professor aprende-se com o manejo da matéria, não "como" manejar a matéria, mesmo quando esse manejo acabe sendo "como" o do professor. Esse "como" é sempre problemático, não apenas porque sugere imitação, reprodução, cópia, mas por designar os próprios meios ou maneiras de criação. A pergunta "chave" de Mil Platôs envolve a explicação de uma maneira de se fazer: "como construir para si um corpo sem órgãos"?

Vulgarmente, maneira pode se confundir com método, pois ambos os termos referem-se a meios de elaboração, construção e criação, entretanto, trata-se de coisas diferentes. Enquanto a ideia de método pressupõe um tanto de racionalismo, "maneira" é um termo que se solidificou na arte, indicando um modo particular de pintar, compor, esculpir, escrever, desenhar. Sua etimologia converge em termos como manuseio, jeito, manipulação. Uma certa maneira pressupõe um certo modo de arranjo, uma certa disposição de elementos heterogêneos, um agenciamento. Enquanto um método quase sempre visa um objetivo específico, uma maneira apenas indica um jeito de tratamento, 
sem finalidades especiais. Mesmo quando se apresenta como "uma maneira de se chegar lá", não é mais método, é estilo. Não se trata de atingir resultado algum que não seja a aberta e inacabada unidade da obra de arte. A especificidade de uma "maneira" diz das qualidades sensíveis que permeiam a arte e contam sobre os encontros nos quais ela aconteceu. Maneiras dizem respeito a condutas, a modos de se conduzir, a toda uma ética que não consegue ser separada da estética. Entre o "como" maneirista e o "como" metodológico, há uma distância abissal. O método tende a ocupar-se de relações causais, ao passo que a maneira é puro efeito de superfície, aparência e ocupação territorial. Fazer a "maneira de", ou ainda "à moda de", é simular um modo, um movimento, um estilo de traçado de plano, um jeito de compor a existência.

O adjetivo "maneirista" e a descrição de um estilo chamado "maneirismo" (o qual frequentemente é descrito como "falta de estilo") aparecem na História da Arte ocidental. Apesar de muitas controvérsias, o Maneirismo diz respeito ao período que sucede o Renascimento, ou que seria a decadência desse e de seus ideais humanistas. Janson situa esse estilo de difícil descrição, que escapa às classificações, nos anos 1525-1600. 0 que o define é a imitação, visto que os pintores dessa época, que também se chama Renascimento Tardio, copiavam os artistas consagrados do auge do Renascimento. Correggio, pintor maneirista, usava o sfumato "à maneira de" Leonardo, Tintoretto pintava “à maneira de" Rafael, etc. Essa produção heterogênea, pós-renascentista, traz consigo as perturbações da consolidação das cidades modernas, da Reforma e do começo da Contra-reforma, das Grandes Navegações e do Mundo colonial. Tintoretto, El Greco, Arcimboldo, Brueghel, Veronese são alguns dos artistas desse estilo, cujo traço característico é grotesco e fantasioso. Abundam desenhos feitos a partir de descrições de animais e plantas exóticos, vistos nas terras selvagens que o europeu moderno se põe a explorar. Os corpos se deformam, alongam-se, desviam-se dos cânones clássicos, as proporções áureas são adulteradas. Um dos quadros maneiristas mais reproduzidos é a Madonna do Pescoço Comprido, do pintor alquimista Parmigiano, a qual Janson diz ser "uma imagem de perfeição extraterrena" (1977, p.449). O que vai tornar-se rebuscado e demoníaco no barroco, aqui ainda é sutileza, rumor imperceptível de um mundo novo e estranho que se aproxima. Em seu estudo sobre o assunto, Hocke contrapõe os monstros gigantes e os animais fabulosos do maneirismo ao racionalismo clássico, dividindo a arte nessas duas manifestações complementares e "absolutas" (2005,p.328). No amplo estudo que faz das artes plásticas, intitulado Maneirismo: o mundo como labirinto, observa a fantasmagoria de uma existência turbilhonar, misteriosa e de difícil compreensão humana mostrando a tendência maneirista, que se "se subtrai à simplificação" (HOCKE, 2005, p.189) como força que extrapola a segunda metade do 
século XVI, sendo possível encontrar maneirismos plásticos, visuais e literários desde a pré-história até a contemporaneidade.

A artificialidade maneirista, a imitação da "originalidade" de modo afetado e teatral, faz com que o termo no dicionário de filosofia de Abbagnano, baseando-se em Kant e Hegel, defina uma "forma menor de expressão artística" (2000, p.641). Na palavra dos críticos, mesmo que para conteste, tal acepção traz a falta de "tarimba" que os artistas maneiristas teriam quando comparados aos grandes mestres (Hocke, 2005, p.43). Sem fazer quaisquer juízos de valor, interessa aqui esta qualidade "menor", que em outros contextos poderia ser dita popular, pop, kitsch, cujos traços claramente inspiram-se no maneirismo. Não necessariamente no Maneirismo, Renascimento Decadente ou Protobarroco da História da Arte, mas todos os maneirismos que movimentaram e movimentam a arte desde então. Mesmo que se faça uma breve incursão arqueológica ao século XVI, o plano que se traça para a Educação e para Arte é composto junto ao que se julga arte "inferior", copiosa e burlesca. Mais do que uma preferência estética, essa escolha se deve a uma posição política: o maneirismo é expressão artística minoritária. Minoritário não tem nada a ver com a abundância de detalhes e outras mínimas elaborações observadas em obras ditas "maneiristas", como podemos observar no compêndio de imagens selecionadas por Emily Grassi (2011), mas sim com os tipos de usos e modos de disseminação rizomáticos implicados nas artes "menores". Junto a este aspecto de rizoma, que podemos visualizar nos motivos decorativos como arabescos de inspiração vegetal, também interessam as características bizarras, extravagantes, afetadas, assustadoras e cômicas da arte. Grotesco, este tipo de expressão artística se faz com artifícios em torno de variedades e, como uma maneira, entre infinitas outras, de agenciamento, é daquelas que mais explicita a vizinhança das criações com o caos.

A maneira é um jeito de habitar o plano e criar coesões e divergências entre as variações caóticas, de contínua velocidade e lentidão, que o compõem. Trata-se de um modo de vida, um jeito de criar, de produzir efeitos estéticos, de estilo. Pode se dizer que maneira e estilo são manejos, provocações sensíveis para comover, conservar a fluidez de certos instantes e mover o estado de coisas ao redor. Em suas aulas, o professor Tomaz Tadeu, aquele que "o que diz é o que acontece com ele" (TADEU, 2002, p.51) lembrava a definição tradicional de estilo, essa "ciência das 'variações', como "maneira peculiar, particular, pessoal" pela qual alguém usa a língua. Deleuze escreve que "temos as crenças, os sentimentos e os pensamentos que merecemos em função de nossa maneira de ser ou de nosso estilo de vida" (DELEUZE, 1976, p.1). A concepção deleuziana não separa vida e estilo, o estilo é modo de habitação, não há plano de imanência que se construa sem estilo. Toda toca, toda casa, todo modo de ocupação e 
tomada de território têm estilo. Tratamento da matéria (DELEUZE, 2006, p.47), o estilo, inseparável da política, expressa as multiplicidades da linguagem e suas variações contínuas. A estratégia micro-política é seguir o phyllum e entrar em deviresimperceptíveis, morar em trânsito, habitando multiplicidades moleculares que tornam estranha a própria língua. Se há um método para se fazer multiplicidades, este método é apenas as maneiras, o estilo; não há separação nenhuma entre "estilo" e "método", ambos se explicam pelas maneiras de conduzir o pensamento no plano. Com a ajuda de personagens e figuras, o estilo explica, coloca para fora o cromatismo e os matizes do mundo atual, estende a linguagem num processo de deslocamento de pontos de vista e produção de séries. Uma explicação é uma maneira de se conferir certa unidade à multiplicidade, é um recorte, um traçado, a definição de um plano dentro do caos. Paradoxalmente, ao se explicar uma obra, é desfeita a unidade que o artista lhe conferiu.

A unidade constituída não passa de efeito, artifício. Toda obra nunca está acabada, mesmo quando o artista a dá por "pronta". De um modo ou de outro, toda unidade é sempre provisória e por isso as explicações gaguejam e criam estranhamentos em sua própria linguagem. Toda unidade atual tende a se esfacelar em multiplicidades virtuais. Fazer "à maneira de Deleuze" é fazer o múltiplo, criar rizoma, bifurcar, extrair virtualidades do plano politonal da experiência, estendido, em que o corpo experimenta o atual. Para isto não basta, como Deleuze, criar junto à literatura, imerso na poesia, na ironia e na tragédia mas, fazer como Deleuze, "à maneira de Proust" a defesa do direito "ao inacabado, às costuras e aos remendos"( 2006, p.161).

Se há um "método" deleuziano, esse é o que chamam de cartografia esquizo-analítica, feita "à maneira de" rizoma. Trata-se de criar um mapa "conectável em todas as suas dimensões, desmontável, reversível, suscetível de receber modificações constantemente" (DELEUZE; GUATTARI, 1995, p.22). Mas mais do que um método de criação, a cartografia é uma maneira de estudar um campo problemático, suas linhas de composição, movimentações e múltiplas entradas. O mapa é rizomático, tem direções movediças que mostram "multiplicidades de pontos de vista sobre o mesmo objeto e troca de pontos de vista sobre vários objetos" (DELEUZE, 2006, p.167), sua função é agenciar o heterogêneo, nunca reproduzir um mundo. Além de discernir os segmentos duros, estratificados, estabelecidos, a cartografia ocupa-se com as bifurcações, linhas de fuga, disjunções, entradas e saídas de diversos fluxos, os quais tornam os territórios suscetíveis a desterritorializações, alterações, mudanças. A cartografia é o estudo dessa problemática instabilidade territorial composta por linhas que remetem umas às outras 
nas mais variadas tendências, velocidades, intensidades e proliferações caóticas, as quais mostram a exterioridade potencial que o interior de um território comporta. O conceito de multiplicidade, importantíssimo para o pensamento da diferença, partilha desses encontros com o fora, com os fluxos novos, selvagens e estranhos que desestabilizam e modificam os territórios discernidos, mapeados. Por isso, mais do que um método de cortes e traçados, a cartografia trata das maneiras pelas quais os fluxos distribuem-se, ou seja, trata das maneiras de devir.

Devir são os processos transversais, minoritários, em que se dão as exterioridades das relações e, portanto, diz respeito às linhas de fuga. Mais do que o curso dos fluxos e seu escape, o devir é a própria proliferação de multiplicidades. Não há singularização sem devir, o devir é o movimento da diferença. O que todos os tipos de devires colocam são as relações com a sexualidade, com as etapas da vida, com os animais, os vegetais, os minerais, com todos os reinos da natureza e com todas as coisas artificiais, com a política, com o livro, e o que mais interessa, com o imperceptível. Sem metas e sem métodos, do devir só extraímos os modos, os tratamentos, as diferentes maneiras de devir. Se "não há diferença entre aquilo de que um livro fala e a maneira como é feito" (DELEUZE; GUATTARI, 1995, p.12), não há como separar a escrita dos múltiplos devires que nela se exprimem.

Apesar da fluidez do devir, o desespero não diminui quando somos incitados a criar uma nova maneira de fazer pesquisa e inventar uma escrita para expressar o que se pesquisa. À maneira de Deleuze e Guattari, tentamos uma escrita que "esposa uma máquina de guerra" (DELEUZE; GUATTARI, 1995, p.35). Não se trata simplesmente de um instrumento bélico contra a estratificação de certos discursos educacionais e outros segmentos molares, que constituem aparelhos de Estado. Exterior aos aparelhos de Estado, as máquinas de guerra dizem respeito a outro modo de vida, não sedentária, com tendência à desterritorialização. As máquinas de guerra são concebidas em função do deslocamento, da mudança constante de posição. Nômades, não fornecem, tal qual encontramos nos aparelhos de Estado, um modelo, "segundo o qual temos o hábito de pensar" (DELEUZE; GUATTARI, 1997, p.15). Um pensamento máquina de guerra conjura os órgãos de poder, cujas regras disciplinares determinam as maneiras de vida. Mundanas, as regras da máquina de guerra "animam uma indisciplina fundamental do guerreiro, um questionamento de hierarquia, uma chantagem perpétua de abandono e traição, um sentido de honra muito suscetível"(idem, p.21). Quando estrategicamente erigidas contra o Estado, impulsionam suas malhas estriadas, lineares, a transbordarem 
e experimentarem um espaço "para o qual não há método possível, reprodução concebível, mas somente revezamentos, intermezzi, relance"(DELEUZE; GUATTARI, 1997, p.47), trocas de partículas e encontros de forças que fazem as máquinas de guerra serem potencialmente criadoras. Seus movimentos remetem à ação livre, ao giro, à ocupação turbilhonar de um espaço que não comporta nenhuma meta preestabelecida, planejada.

Por um momento, não mais do que um instante fugaz, acredita-se ter encontrado uma solução: nomadizar, deixar-se levar pelos devires, buscar micrologias, ir atrás das linhas de fuga, das distribuições no espaço aberto, indeterminado, sem partições, cercados ou fronteiras. Enfim, seguir agenciamentos que façam o pensamento viajar. Entretanto, a viagem não pode ser empreendida a partir de direções cardinais, de baixo para cima, da esquerda para a direita, pois é uma percepção das coisas que parte daquilo que está entre elas, que parte do meio. Tudo muda, frente à desconfortável perspectiva nômade, sem começo nem fim, a qual seguimos ao acaso do devir. Mas isso implica jamais fazer desse seguimento uma regra ou lei, transformá-lo em uma imagem dogmática, em modelo de pensamento ou metodologia. Não sem desespero, voltamos à estaca zero.

Sem saber o que fazer, experimenta-se uma infinidade de possíveis, a lisura do espaço in-formado, de tudo o que ainda não foi. Vive-se na carne o devir-errante estudado em teoria. Descobre-se que o espaço liso, as estepes, os desertos, a vastidão oceânica e a imensidão da Amazônia não são nada reconfortantes: as linhas de fuga traçadas pelas máquinas de guerra podem virar linhas de perdição, de abolição. Linhas de morte. Além de criadora, a máquina de guerra também é mortal. Não apenas na estranheza de territórios inabitáveis, no impensado do espaço liso, o aspecto mortífero também acontece quando, no encontro com o aparelho de Estado, a máquina de guerra o ataca (afecto projetivo, violência intrínseca do bando). Dependendo do embate, a máquina de guerra pode se destruir ou ser obrigada a traçar uma linha de escape que a leve para longe dos diagramas do Estado; pois, caso não se torne maior e mais potente que o próprio aparelho quimérico, acaba sendo engolida por este e deixa de ser máquina de guerra. Se resistir, vira guerrilha; incorporada, torna-se instituição militar. Anterior aos aparelhos de Estado, o nomadismo é primeiro e tem mais a ver com a radiestesia do que com a necessidade de conquistar territórios. Seja em direção ao espaço liso selvagem ou ao espaço compartimentado da civilização, a máquina bárbara segue os fluxos das riquezas extraídas do solo. O devir-metal das máquinas de guerra não implica apenas a produção de artefatos bélicos, mas a fabricação de ferramentas e peças de joalheria. 
Pensar a prática de pesquisa como ourivesaria é uma das ideias de Sandra Corazza (2002, p.105-131). No texto escrito para a coletânea Caminhos Investigativos, os múltiplos métodos dos quais dispomos são tratados como processos de alquimia e bricolagem, os quais funcionam como pontes que tamponam falhas entre as construções históricas e culturais. A autora insiste que o cansaço "do já-sabido" é aquilo que nos impele à investigação. Não querer trilhar os caminhos já traçados, as pontes já construídas, obriga o pesquisador a transgredir as metodologias, saltar de um lugar ao outro e criar uma "pluralidade imetódica". Tal criação implica assumir pontos de vista ainda não perspectivados e pular para "o abismo, para o buraco, para o desconhecido", único lugar onde "é possível produzir abalos; provocar mudanças no que somos capazes de ver e dizer; dar alegres cambalhotas; radicalizar nossas relações com o poder e o saber; partir as linhas; mudar de orientação; desenhar novas paisagens; promover outras fulgurações. Homem "do subsolo", o itinerante "primeiro e primário" (DELEUZE;GUATTARI, 1997, p.95) é o artífice, aquele que segue o devir-mineral, produtividade pura da matéria - fluxo. Devido a suas relações peculiares com a matéria e suas potências imanentes, o artífice segue "objetos por excelência", transforma territórios, ao pensar e criar junto com o impensado, anterior ao zero.

Frente ao que ainda não foi visto, do que ainda não foi dito, o problema não é reproduzir, usar um modelo ou copiar um estilo; é impossível criar do nada, o nada só pode criar nada. Os modelos, árvores do conhecimento e outras imagens dogmáticas, podem produzir usos novos, estranhos, visto que esses quase sempre encarnam "temas, figuras e personagens que os ultrapassam", na medida em que toda obra versa sobre temas, "arquétipos involuntários, dos quais as palavras, como as cores e os sons, tiram o seu sentido e a sua vida"(DELEUZE, 2006, p.47). Tais temas oferecem nomes próprios, tais como Anticristo, Dionísio e Zaratustra, que designam intensidades, as quais só podem ser vividas sobre um corpo pleno de perpétuos deslocamentos: “corpo da terra, o corpo do livro e também o corpo sofredor de Nietzsche"(DELEUZE,1985, p.63). Não se trata de significações, significados, representações de coisas ou de palavras e sim de fazer as imagens temáticas entrarem em devir. No decorrer de sua obra, Deleuze e Guattari insistem na importância dos problemas de produção e funcionamento maquínicos, indicando sempre que não se trata do que uma máquina representa ou significa e sim de como ela funciona. "O problema não é de sentido, é de uso" (1996, p.81). A problemática vem da maneira pela qual os temas proliferam, jamais do tema e dos nomes próprios e sim dos personagens conceituais e figuras estéticas que os animam. Sem motivos temáticos, figuras, personagens, sem as tonalidades e matizes das 
sensações experimentadas no plano de imanência e na matéria caótica que lhe concerne, é impossível criar. Mas somente com os motivos temáticos não se cria, apenas se reproduz. Para criar é preciso retirar tudo, esvaziar, afugentar os fantasmas e liberar a matéria intensa, não formada, "ovo pleno" (DELEUZE; GUATTARI, 1996, p. 13-14) da intensidade grau zero.

Nessa intensidade, instante novo, ponto zero da criação, cuja linha faz o corpo sem órgãos, acontece a última metamorfose da máquina de guerra. É sua transformação em máquina de arte, a passagem da arma para a ferramenta e a clara definição das formas e usos de cada uma. Esta metamorfose indica as permutações, os revezamentos, oscilações entre planos distintos, relações entre artefatos e arquitetura, estilos. Movimento reterritorializador, a arte atenua as tensões intrínsecas que compõem a máquina de guerra, na medida em que se firma em seu aspecto produtor e não em seu potencial destruidor, apesar de jamais eliminar os perigos abissais que envolvem sua inevitável proximidade com a loucura e com a morte. Nesse último avatar, grau zero que, paradoxalmente, é também primeiro, a máquina de guerra é esposada pela escrita deleuziana.

Para entrar nessa escritura nômade, fazer textos que sejam efetivamente máquinas de guerra da arte, só temos duas pistas (por favor, não as confundam com garantias de esperança), as quais se aprende, não apenas junto à escrita do próprio Deleuze, mas também, na experimentação do espaço liso, frente à superfície vazia, plena de possíveis, a qual somos obrigados a preencher com palavras. A primeira delas, sem a qual não podemos reinventar a escrita educacional e nem pensar uma outra maneira de se fazer educação, é a proximidade com a arte. Nenhum texto nos apaixona, nos eleva, faz pensar ou vibrar, se não manipular a dimensão imaterial dos signos da arte; arte cujo plano de composição é uma máquina produtora de efeitos envolventes. A segunda pista, sobre a qual Deleuze e Guattari dedicaram todo um platô, o primeiro de todos os platôs, é que a feitura de plano textual se dá por conexões, faz rizoma. "Qualquer ponto de um rizoma pode ser conectado a qualquer outro e deve sê-lo (DELEUZE;GUATTARI, 1995, p.15), sendo que um texto assim parte do meio, "não começa nem conclui", é puro intermezzo (DELEUZE; GUATTARI, 1996, p.37), que conecta todas suas instâncias umas nas outras, nas mais variadas relações de heterogeneidade. "Peça para todas as máquinas móveis" (DELEUZE; GUATTARI, 1995, p.36), os textos rizomáticos fazem uma ruptura a-significante, a qual se manifesta contra cortes e separações radicais entre as 
estruturas. Corte que potencializa a diferença, cria alteridade, abre outra opção, recebe a novidade. A diferença, em suas qualidades heterogêneas, cria multiplicidades.

Criar rizomas, bifurcar, é traçar linhas, diferir um ponto do outro, com diferentes variações de intensidade e velocidade. Ser rizomorfo é também criar arborescências, "produzir hastes e filamentos que pareçam raízes, ou melhor ainda, que se conectem com elas penetrando no tronco" (DELEUZE; GUATTARI, 1995, p.25). A esquizoanálise descreve dois ou três tipos de linhas, das quais interessam as "linhas de fuga", as que proliferam nas zonas marginais. Seguir as linhas de fuga é mapear as travessias para o território esquizofrênico, louco, daquilo que é impossível de ser educado, domesticado e valorado.

Privilegiar esse território como solo fértil para a criação não é fazer a apologia da arte e suas loucuras, e sim pensar os movimentos que fazem as multiplicidades e suas conexões e desvios, a fim de se mapear os riscos que envolvem uma experimentação real. Como um agenciamento maquínico beira muitos perigos, a esquizoanálise procura saber quando as linhas de fuga tornam-se mortíferas, quando as criações são fatais e o tipo de riscos que se corre em algumas experiências. Experimentar o impensado, o incriado, in-formado, não apenas arrasta à afecções desesperadoras, mas constitui um agenciamento dionisíaco, traçado por linhas estranhas, monstruosas. Sem formas ou imagens, as relações de forças do dionisíaco arrasam os referenciais junto aos quais estamos acostumados a operar, com os quais constroem-se imagens de pensamento. Fazer uma cartografia dos agenciamentos pedagógicos feiticeiros, desterritorializantes, que germinam as paranoias do delírio passional, é mapear principalmente quedas e depressões que cortam radicalmente os territórios. É preciso “apelar para reservas de uma vontade verdadeiramente desesperada"(ARTAUD, 1986, p.101) numa esquizoanálise do abismo e de todos seus monstros potenciais. Como Artaud, é viver a proximidade com a loucura e com a vertigem criadora da arte, deixando-se ser "montado e desmontado como um autômato desamparado" (idem, p.108), supliciar-se na linguagem, perder-se no texto. Mais do que seguir linhas de fuga, cartografar os agenciamentos dionisíacos é também estudar a topologia do desmembramento e a tipologia da aniquilação. Experimentar a reversibilidade das linhas de morte e o jogo mágico que as transforma em linhas vitais. 


\section{Referências}

ABBAGNAMO. Dicionário de Filosofia. São Paulo: Martins Fontes, 2000

ARTAUD. Escritos de Antonin Artaud. Porto Alegre: LP\&M, 1986.

CORAZZA, S. Labirintos da pesquisa, diante dos ferrolhos. In: Caminhos investigativos: novos olhares na pesquisa em educação, v.1. Rio de Janeiro: DP\&A, 2002.

DELEUZE. Proust e os signos. Rio de Janeiro, Forense Universitária, 2006.

DELEUZE. Pensamento nômade. In: MARTON. Nietzsche hoje? São Paulo: Brasiliense, 1985.

DELEUZE. Nietzsche e a filosofia. Editora Rio, 1976.

DELEUZE. Diferença e repetição. Rio de Janeiro: Graal, 1988.

DELEUZE; GUATTARI. O anti-édipo: capitalismo e esquizofrenia. Lisboa: Assírio e Alvim, 1996.

. Mil platôs v.1. Rio de Janeiro: Ed.34, 1995.

Mil platôs v.3. Rio de Janeiro: Ed.34, 1996.

Mil platôs v.5. São Paulo: Ed, 34, 1997.

GRASSI, Emily. Manierismo. Trad. Alessandra Angelini. Firenze: Scala/E-ducation.it., 2011.

HOCKE, Gustav R. Maneirismo: o mundo como labirinto. Trad. Clemente Mahl. São Paulo: Perspectiva, 2005.

JANSON. História da Arte: panorama das artes plásticas e da arquitetura da préHistória à actualidade. Lisboa: Fundação Calouste Gulbenkian, 1977.

PASCAL, Georges. Descartes. São Paulo: Martins Fontes, 1990.

TADEU, Tomaz. A arte do encontro e da composição: Spinoza + currículo + Deleuze. Educação e Realidade, Porto Alegre - RS, v. 27, n.2, p. 47-57, 2002. 
Paola Zordan (UFRGS/RS)

Professora do Instituto de Artes da UFRGS. Doutora em Educação. Faz parte do grupo de pesquisa DIF: artistagens, fabulações e variações, desenvolvendo temas que envolvem historiografia da arte, formação de professores e esquizoanálise. Licenciada em Educação Artística, bacharel em Desenho, foi professora de artes em escolas básicas da rede de ensino em Porto Alegre. Endereço institucional: Rua Senhor dos Passos, 248, CEP 90020180 - Centro - Porto Alegre, RS. Endereço eletrônico: paola.zordan@gmail.com

Recebido em: 25/07/2014

Aprovado em: 08/08/2014 